\title{
Age-dependent and radial sectional differences in the dynamic viscoelastic properties of bamboo culms and their possible relationship with the lignin structures
}

\author{
Yoko Okahisa ${ }^{1 *} \mathbb{D}$, Keisuke Kojiro², Hatsuki Ashiya², Takeru Tomita², Yuzo Furuta², Masaomi Yamamura ${ }^{3}$ \\ and Toshiaki Umezawa ${ }^{3,4}$
}

\begin{abstract}
Age is an important factor that dictates bamboo's mechanical properties. In Japan, bamboo plants aged 3-5 years are selected for use as materials because of their robustness and decorative or craft-friendly characteristics. In this study, the age-dependent and radial sectional differences in bamboo's dynamic viscoelastic properties in relation to lignin structural variation, were evaluated. We used Phyllostachys pubescens samples at the current year and at 1.5, 3.5, 6.5, $9.5,12.5$, and 15.5 years of age. There was a clear age dependence in the peak temperature of $\tan \delta$ and in the yield of thioacidolysis products derived from $\beta$-O-4 lignin structures. The highest peak temperature $\tan \delta$ value was detected in 3.5-year-old bamboo, which contained the highest amount of the thioacidolysis products. Moreover, $\tan \delta$ 's peak temperature was always higher on the outer side, and the ratio of $S / G$ thioacidolysis products was always higher on the inner side of bamboo plants of all ages. These results suggest that changes in bamboo's thermal softening properties from aging are caused by the maturation and degradation of lignin in bamboo.
\end{abstract}

Keywords: Bamboo, Phyllostachys pubescens, Dynamic viscoelasticity, Lignin structure, Age-dependent changes

\section{Introduction}

Bamboos are a group of woody grasses that grow widely from tropical to temperate zones with wet seasons and are important economical materials. There is an optimal age for harvesting bamboo. In Japan, bamboo plants at the age of 3-5 years are selected for use because of their robustness and decorative or craft-friendly characteristics. Moreover, in China, 5- to 6-year-old bamboo plants are selected for harvesting in well-managed bamboo forests [1]. Age is an important factor dictating bamboo's mechanical properties [2]. In our previous study, it was suggested that the age-dependent changes in the

\footnotetext{
${ }^{*}$ Correspondence: okahisa@kit.ac.jp

1 Fiber Science and Engineering, Kyoto Institute of Technology, Kyoto 606-8585, Japan

Full list of author information is available at the end of the article
}

microfibril angles may affect these mechanical changes [2] as well as the density of the entire culm and the thickness of the cell walls $[3,4]$. However, these results should be considered with other factors because the variation in mechanical properties in bamboo may also be affected by some changes in lignin quality [3].

Among bamboo's mechanical properties, the dynamic viscoelastic characteristics are important, especially for straightening bamboo after heating and cooling processes [5]. Kiryu et al. [3] reported that the dynamic modulus of elasticity and the loss modulus of elasticity increased, and their temperature dependence changed with the bamboo's increasing age. Studies of plant cell walls have suggested that the temperature dependence of the dynamic viscoelasticity is affected by the presence of lignin [6-10]. It was reported that the major transition in the temperature range $20-140{ }^{\circ} \mathrm{C}$ at 0.05 and $20 \mathrm{~Hz}$ of wood under 
water-saturated conditions is related to a glass transition of the in situ lignin [10]. The storage modulus of elasticity of water-saturated wood and bamboo from 20 to $100{ }^{\circ} \mathrm{C}$ decreased with the decrease in their lignin content [11], which implies that the thermal softening largely depends on lignin content. Moreover, these thermal softening temperatures differed between softwood and hardwood [11]. The transgenic switchgrass plants with lignin modification for increasing fermentative sugar yields reduced the glass transition temperature as well as plants stem stiffness and strength [8]

Lignin is a phenylpropanoid polymer that is biosynthesized via oxidative coupling of p-hydroxycinnamyl alcohols (monolignols) and related compounds [1214]. Lignin formed by coniferyl alcohol polymerization is guaiacyl (4-hydroxy-3-methoxyphenyl, G) type, while syringyl (3,5-dimethoxy-4-hydroxyphenyl, S) and p-hydroxyphenyl (4-hydroxyphenyl, $\mathrm{H}$ ) types are formed by polymerization of sinapyl and p-coumaryl alcohols, respectively. In gymnosperms, especially the secondary xylem of softwood trees, lignin is almost entirely composed of $G$ units with small amounts of $H$ units $[15,16]$. The lignin polymer in dicot plants is primarily made up of $G$ and $S$ units with small amounts of $H$ units $[15,17]$. In this regard, however, lignin of hardwood or secondary xylem of dicot trees is exclusively composed of $G$ and $S$ units with trace amounts of $H$ units $[16,18]$. Gramineous lignins consist mainly of $\mathrm{G}$ and $\mathrm{S}$ units with a slightly higher number of $\mathrm{H}$ units than dicot lignins $[15,16,18$, 19]. Additionally, gramineous lignin is typically acylated with p-coumarate $[15,19,20]$. Moreover, recently, a flavone, tricin, was found to serve as one of starter units of lignin polymerization in gramineous plants $[19,21]$.

Lignin deposition starts approximately over the 3 months following shooting, when the ratio of cell wall components becomes constant. However, bamboo has multilayered, polylamellated cell walls to which new layers are added (resulting in an increase in cell wall thickness) as the bamboo ages. This addition of new layers is observed over a period of 3-5 years after shooting [22]. Liese and Weiner [23] suggested that cell wall formation continues even in 12-year-old culms. It was also reported that the amount of cellulose, hemicellulose, and lignin per unit area increased over a period of 9 years after shooting [3]. This indicates that lignin is deposited constantly over several years. Tsuyama et al. [24] reported that the formation rate of $\beta-O-4$ linkages and $S / G$ ratio may differ during development of bamboo. In our previous study, it was found that the age-dependent changes in the microfibril angles of cell walls could be important factors related to the mechanical properties of bamboo [2]. Lignin is deposited by inserting in hemicellulose filled a space in cellulose microfibrils [25]. The changes of microfibril angles with age in bamboo could be related to lignin structures. Lignin's structure may change with increasing age and might affect their viscoelastic properties. Moreover, the microfibril angle was always greater in the inner side of the bamboo [2]. Bamboo culms consist of an epidermis, cortex, ground tissue, and lacuna. The ground tissue comprises vascular bundles of fibers embedded in parenchymal cells. The percentage of vascular bundles decreases from the outer to the inner side of the culm. The differences of lignin structures between parenchyma and fiber cells also might affect their viscoelastic properties. In this study, we investigated the dynamic viscoelastic properties of bamboo culms at different ages and sections, i.e., inner and outer side. Moreover, a lignin analysis, via chemical degradative methods, was performed using bamboo specimens collected from the culm that was used in the dynamic viscoelasticity test. We observed age-dependent and radial sectional differences in bamboo's dynamic viscoelasticity and identified their potential relationship with lignin structural changes.

\section{Materials and methods}

Materials

The specimens used to measure dynamic viscoelasticity and analyze lignin are shown in Fig. 1. Moso bamboo (Phyllostachys pubescens Mazel) culms were harvested in November 2017 at a bamboo plantation located in Kyoto, Japan. Six-month-old (0.5Y) and 1.5 (1.5Y), 3.5 (3.5Y),

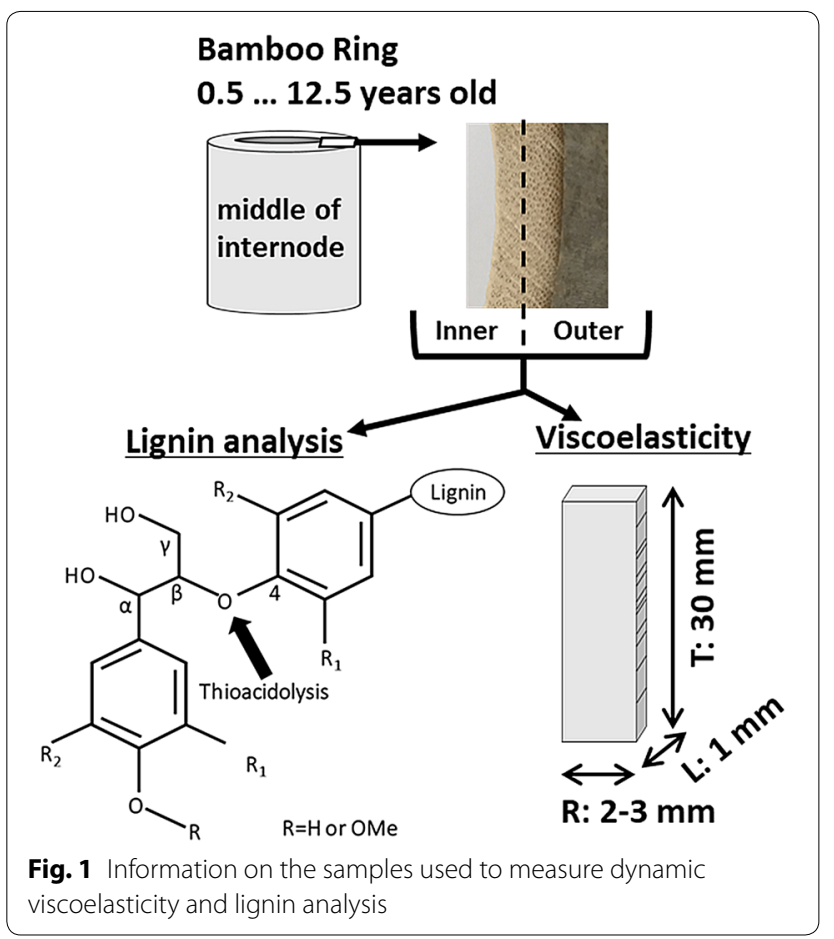


6.5 (6.5Y), 9.5 (9.5Y), 12.5 (12.5Y), 15.5 (15.5Y)-year-old plants were selected. Bamboo culms are thin-walled, hollow cylinders that are separated by nodes. Bamboo rings obtained from the 9th node from the bottom were used in this study. Test specimens were cut from the middle of the internode. Bamboo specimens measuring $1 \mathrm{~mm}$ $(\mathrm{L}$, longitudinal $) \times 2-3 \mathrm{~mm}(\mathrm{R}$, radial $) \times 30 \mathrm{~mm}(\mathrm{~T}$, tangential) were prepared from the inner and outer sides of the culm after removing the epidermal tissues and were used to measure dynamic viscoelasticity. The specimens obtained from the inner side were enriched for parenchymal cells, whereas those from the outer side were enriched for bast fibers. Powder samples were also prepared from the same bamboo rings, which were obtained from the 9th node from the bottom, to be used in lignin analyses.

Measurement of dynamic viscoelasticity

The moisture content strongly affects the plastic working of woody materials containing cellulose, hemicellulose, and lignin [26]. In this study, water-saturated bamboo specimens were used to measure dynamic viscoelasticity. The temperature dependence of the storage elastic modulus $\left(E^{\prime}\right)$ and the loss modulus $\left(E^{\prime \prime}\right)$ were measured in the tangential direction via the tensile forced oscillation method, using an automatic dynamic viscoelastometer (Seiko Instruments, DMS6100). The measurements were performed in water over a temperature range of $20-95{ }^{\circ} \mathrm{C}$ for water-saturated specimens at a heating/cooling rate of $1{ }^{\circ} \mathrm{C} / \mathrm{min}$. The measurement span was $10 \mathrm{~mm}$. The heating and cooling cycle was repeated twice. The growth stress was released, and water-soluble components were leached during the first heating events $[27,28]$. The temperature dependence of dynamic viscoelasticity varies significantly depending on the sample's heat history [11]. In this study, measurements were performed during the second heating cycle. The frequencies used for the measurements were $0.05-1 \mathrm{~Hz}$ with combined wave. The measurements were conducted, and it was confirmed that the response of the traces was essentially reproducible.

\section{Lignin analysis}

Powder samples were exhaustively extracted with water, then ethanol to recover an extractive-free samples. The lignin content of the extracted-free samples was determined based on the amount of thioglycolic acid lignin, as described by Suzuki et al. [29].

Lignin structure was evaluated by thioacidolysis, which is being used increasingly to characterize lignin. The method employs an acid-catalyzed reaction to depolymerize lignins through $\beta-O-4$ cleavage and derives $\mathrm{H}, \mathrm{G}$, and $S$ thioacidolysis monomers (Fig. 2). In this study, the extracted-free samples were subjected to thioacidolysis according to a previously described procedure [30, 31].

The average values \pm standard deviations of thioglycolic acid content, yield of thioacidolysis and S/G ratio were evaluated using results of three replicates.

\section{Results \\ Dynamic viscoelastic properties}

The $E^{\prime}, E^{\prime \prime}$, and the $\tan \delta$ of the $0.5 \mathrm{Y}, 3.5 \mathrm{Y}$, and $12.5 \mathrm{Y}$ culms at $0.05 \mathrm{~Hz}$ are shown in Fig. 3, whereas Fig. 4 depicts the peak temperature of the $\tan \delta$ in all samples. The outer side of culms showed higher $E^{\prime}$ and $E^{\prime \prime}$ values compared with the inner side in all-age bamboo samples.

The peak temperature $\tan \delta$ value, i.e., $E^{\prime \prime} / E^{\prime}$, was also higher in the outer side in all-age bamboo culms. There was a clear age dependence in the peak temperature tan $\delta$ value in samples from both the inner and outer sides. A higher peak temperature $\tan \delta$ value was observed in samples from $1.5 \mathrm{Y}$ and $3.5 \mathrm{Y}$, at $\sim 84{ }^{\circ} \mathrm{C}$ for the inner and $\sim 85^{\circ} \mathrm{C}$ for the outer side. For the inner side, the peak temperature $\tan \delta$ value in the $0.5 \mathrm{Y}, 6.5 \mathrm{Y}$, and later samples was $\sim 81-82^{\circ} \mathrm{C}$, whereas for the outer side, this value was $\sim 83^{\circ} \mathrm{C}$ in the $0.5 \mathrm{Y}, 9.5 \mathrm{Y}$, and $15.5 \mathrm{Y}$ specimens.

\section{Lignin structures}

Lignin content was higher on the outer vs. the inner side in all-age specimens (Fig. 5), whereas the lowest content was detected in $12.5 \mathrm{Y}$, with no clear age trends.

The yield of thioacidolysis, calculated in micromole of monomers per gram of thioglycolic acid lignin, is shown in Fig. 6. Compared with the outer side, the yield of thioacidolysis monomers released from the inner side of samples was comparable or higher in all-age culms. The yield of thioacidolysis monomers in $3.5 \mathrm{Y}$ samples was higher than that observed for other ages. For the inner side, the yield increased from $0.5 \mathrm{Y}$ to $3.5 \mathrm{Y}$, decreased at $6.5 \mathrm{Y}$, and remained constant at older ages. For the outer side, there were no differences between $0.5 \mathrm{Y}$ and $1.5 \mathrm{Y}$. A maximum yield was detected at $3.5 \mathrm{Y}$, similar to that observed for the inner side, after which it decreased up to $9.5 \mathrm{Y}$ and remained constant at older ages.

The ratio of S/G thioacidolysis monomers was higher on the inner side and varied with age (Fig. 7). The S/G ratio in the samples from the outer side was stable from $0.5 \mathrm{Y}$ to $15.5 \mathrm{Y}$ compared with the inner side.

\section{Discussion}

The measurement of the dynamic viscoelasticity and lignin analysis revealed clear differences between the inner and outer side of bamboo culms. These differences may have stemmed from the tissue structure of bamboo. The percentage of vascular bundles with a thicker cell wall layer was higher on the outer side, and the number 


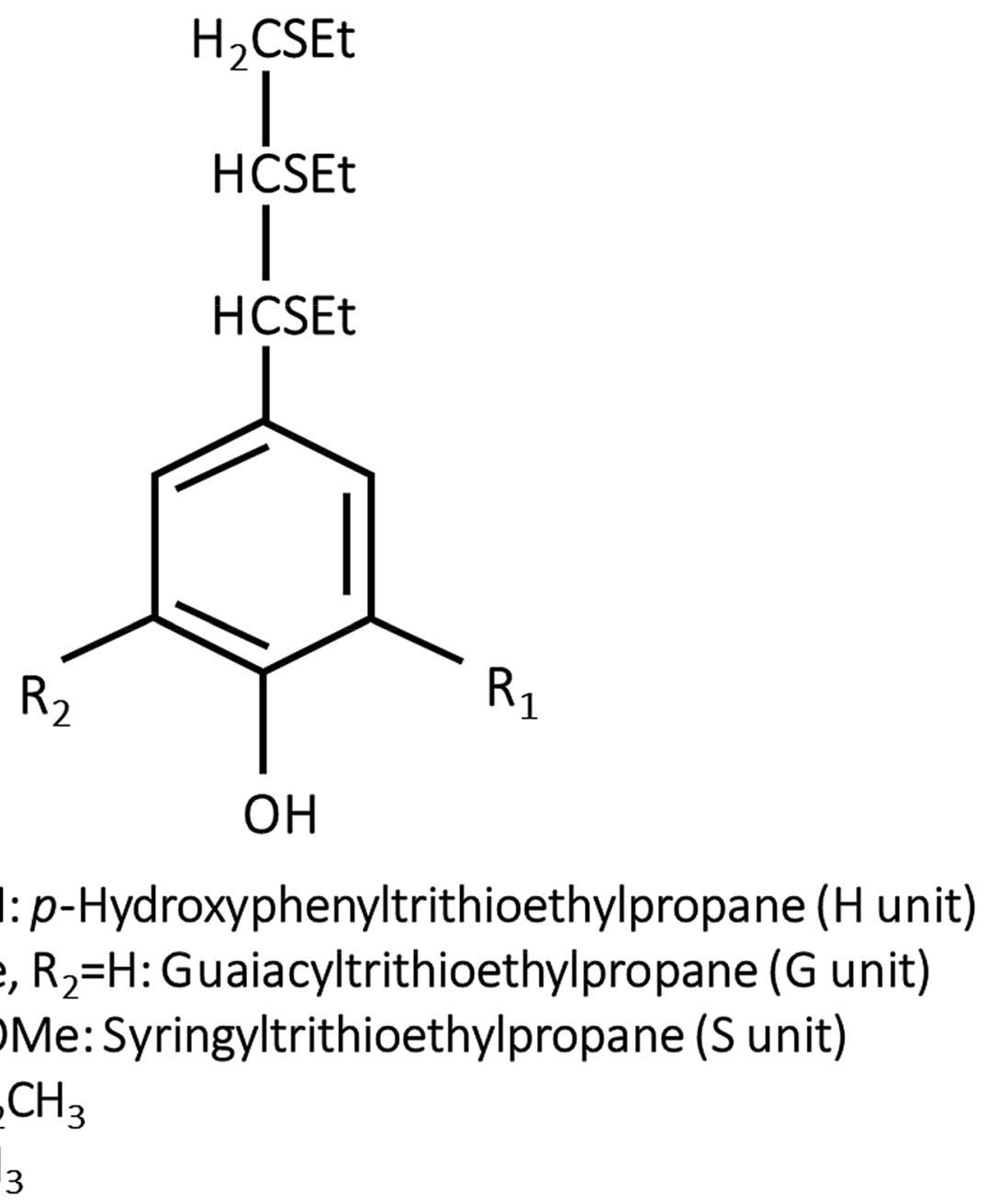

Fig. 2 Major products obtained by the thioacidolysis of native lignin

of parenchyma cells with a thinner cell wall layer was higher on the bamboo's inner side (Fig. 1). Huang et al. [24] revealed the Moso bamboo density of the internodes parts and the nodes parts reduce from the external surface to the internal surface of the culm wall in the radial direction by anatomical analysis and computed tomography scanning quantifications. They also indicated that the different proportions of the vascular bundle tissues and the parenchyma ground tissues dominate the density variation of the Moso bamboo in the radial direction. In this study, the fiber content calculated by the area of the dark vascular bundles (Fig. 1) was 8.6-15.4\% in inner side and $28.0-38.2 \%$ in outer side. The higher fiber contents in outer side lead to higher density than the inner. The basic density of inner side was $0.39-0.58 \mathrm{~g} / \mathrm{cm}^{3}$ and outer side was $0.56-0.68 \mathrm{~g} / \mathrm{cm}^{3}$ in this study. The Young's modulus of the vascular bundle sheath and parenchyma cells in moso bamboo was 48 and $0.26 \mathrm{GPa}$, respectively [32].
In this study, the $E^{\prime}$ values at room temperature were higher on the outer side because of the high contents of vascular bundles with density cell walls in outer side. On the other hand, the differences of the $E^{\prime}$ values between outer and inner side reduced at higher temperature over the glass transition temperature for lignin. This indicates that lignin contributes the differences of $E$ ' value between outer and inner side. The peak temperature $\tan \delta$ value of the outer side was also higher than that of the inner side. The lignin contents and the frequency of $\mathrm{G}$ thioacidolysis monomers was higher on the outer vs. the inner side of bamboo (Figs. 5, 7) regardless of bamboo ages. It seems that the higher peak temperature $\tan \delta$ value observed on the outer side stemmed from a higher lignin contents and ratio of $\mathrm{G}$ units on the outer side, i.e., a higher ratio of resistant interunit bonds (Figs. 8, 9). It was noticed that the glass transition temperature of Populus wood was 

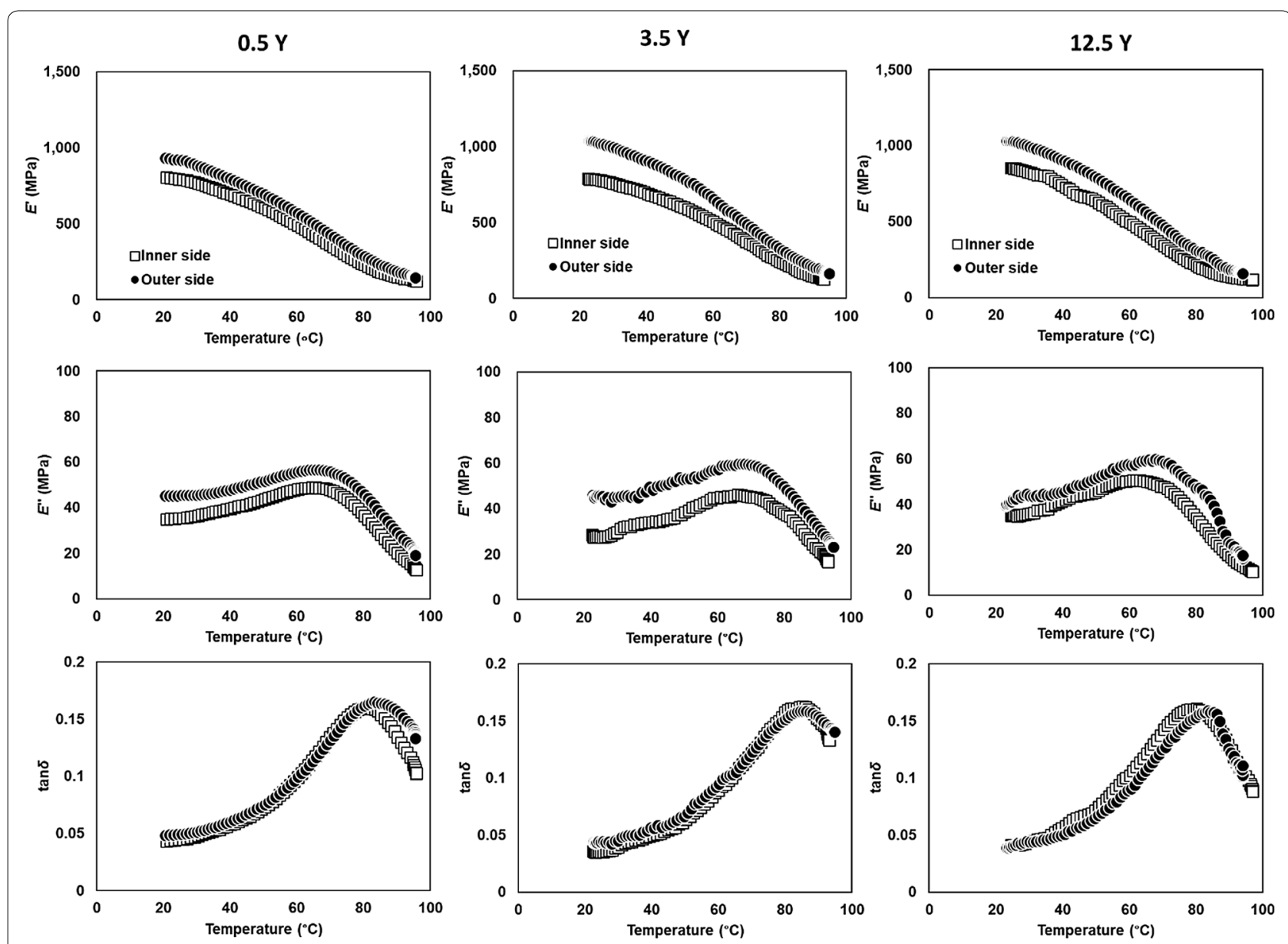

Fig. 3 Temperature dispersion of the storage elastic modulus $\left(E^{\prime}\right)$, loss modulus $\left(E^{\prime \prime}\right)$, and the $\tan \delta$ of the 0.5 -year-old $(0.5 Y)$, 3.5-year-old (3.5Y), and 12.5-year-old (12.5 Y) bamboo culms at $0.05 \mathrm{~Hz}$

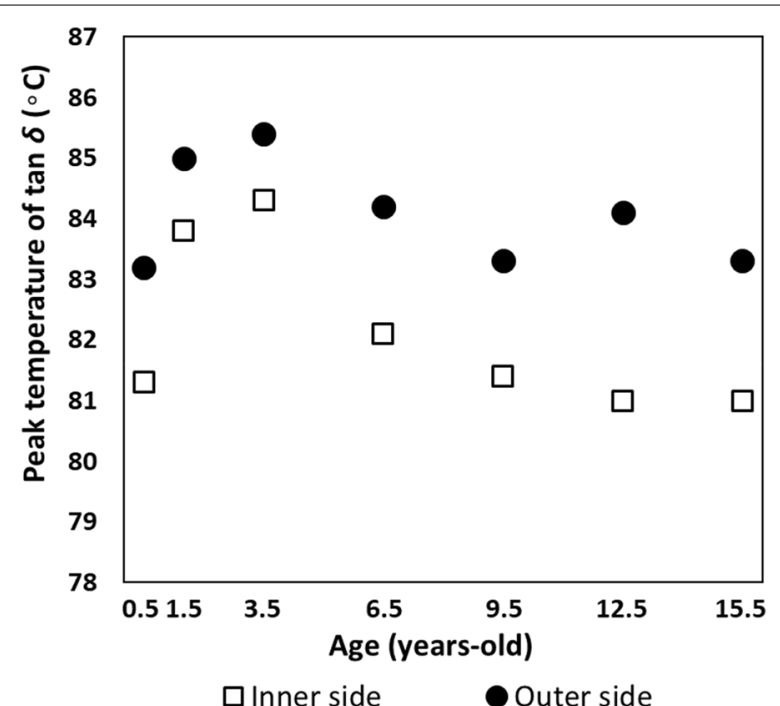

Fig. 4 Peak temperature $\tan \delta$ value of bamboo samples at $0.05 \mathrm{~Hz}$

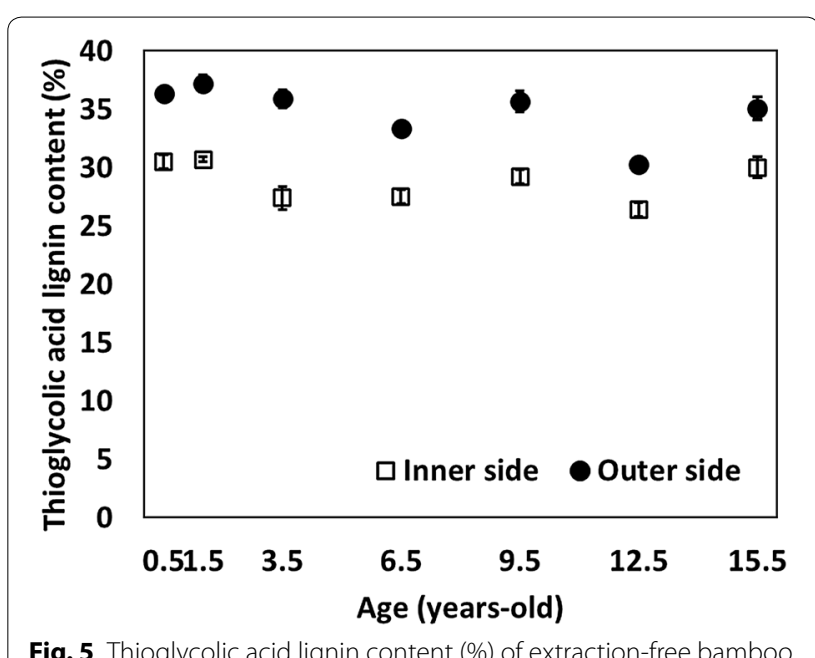
samples 


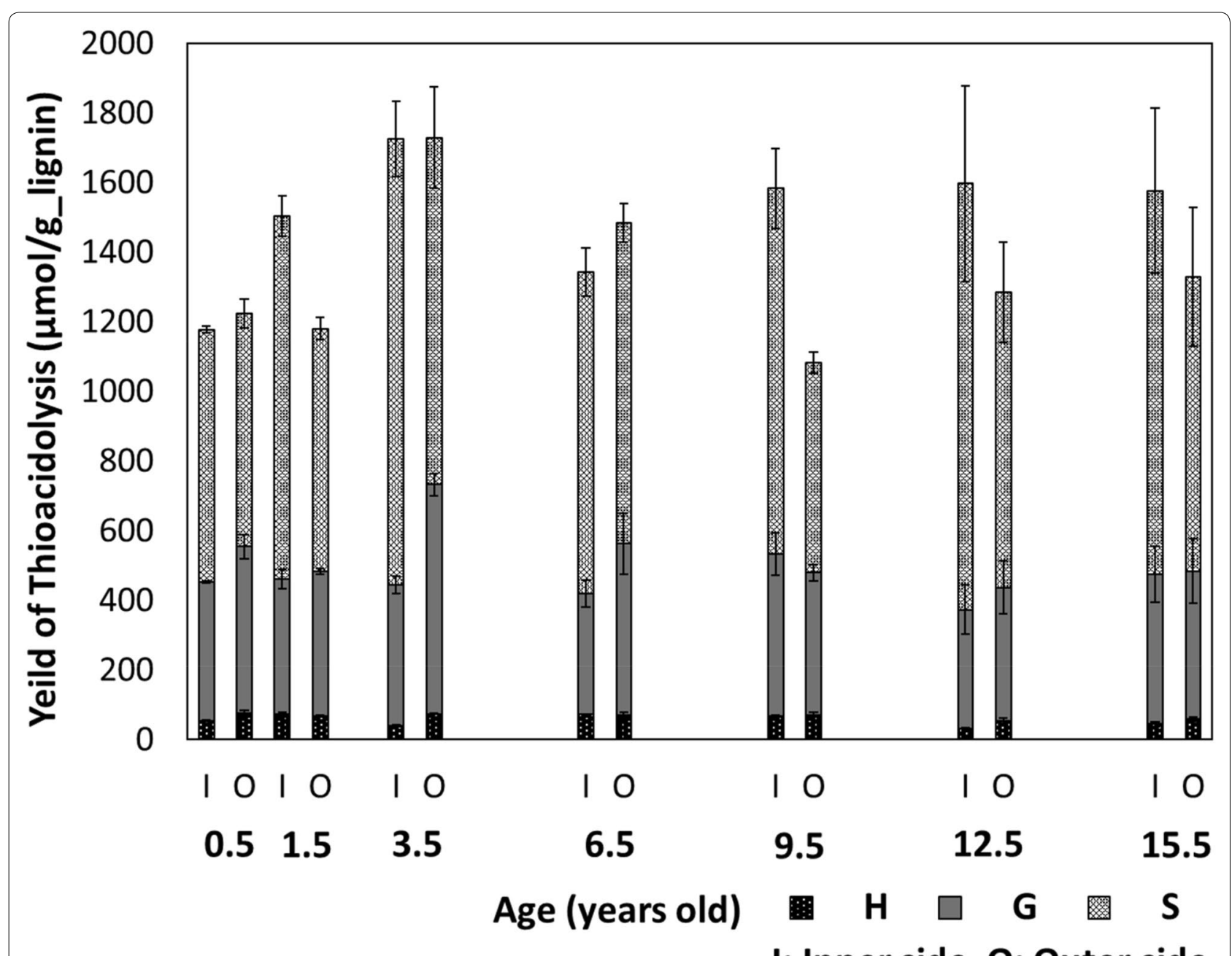

Fig. 6 Lignin-derived H, G, and S monomers released by the thioacidolysis of bamboo samples and total thioacidolysis yield, calculated in micromole of monomers per gram of thioglycolic acid lignin

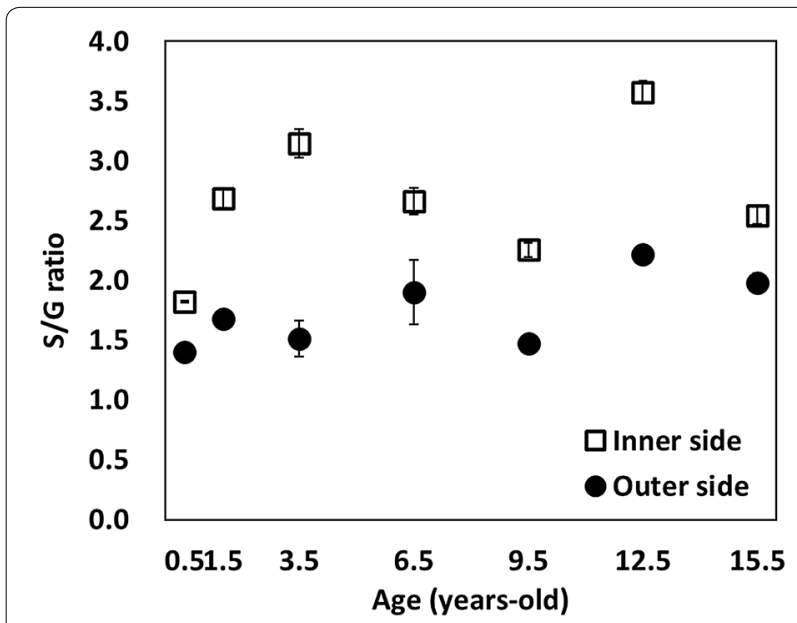

Fig. 7 Ratio of $S / G$ thioacidolysis monomers obtained from bamboo samples retained when the contents of lignin were reduced with maintaining $\mathrm{S}$ to $\mathrm{G}$ ratio [33]. It was also suggested that the increasing $\mathrm{S}$ to $\mathrm{G}$ ratio of wood promotes a lowering of the glass transition temperature of lignin [9]. G lignin units are prone to participate in resistant interunit bonds because of their free C5 position [34, 35]. Having a substantially reduced quantity of G-monomers, the lignin in the transgene positive plants was more flexible, either because of less lignin crosslinking, and/or because of the greater free volume associated with the dominant S-monomers [9]. According to the study with transgenic Populus wood, it was suggested that the glass transition temperatures of lignin were affected by the number of lignin units involved in the $\mathrm{C}-\mathrm{C}$ bonds and lignin molecular weight [36]. The higher peak temperature of $\tan \delta$ value in the outer side of bamboo could be due to 


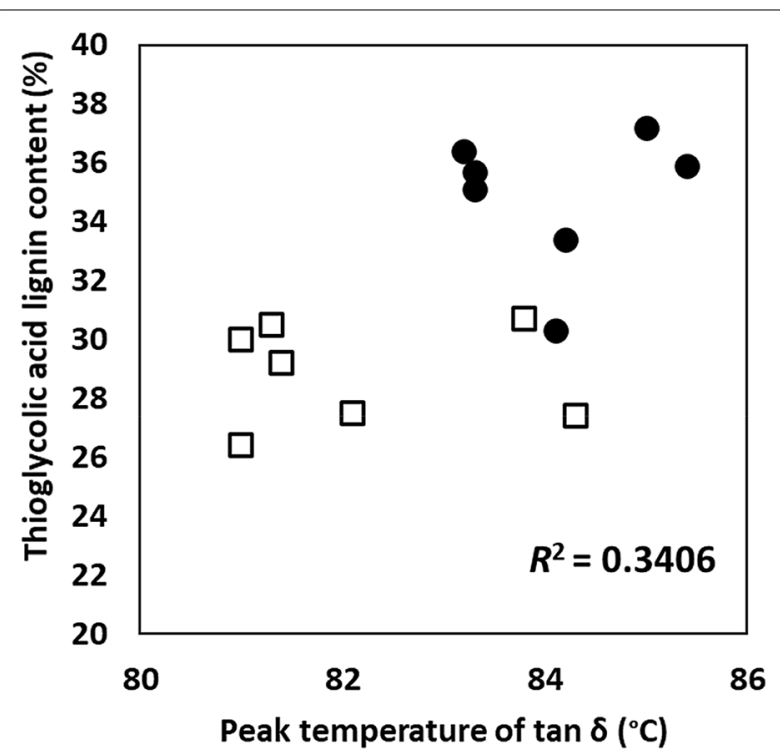

Fig. 8 Relationship between the peak temperature $\tan \delta$ value and the lignin content of bamboo samples

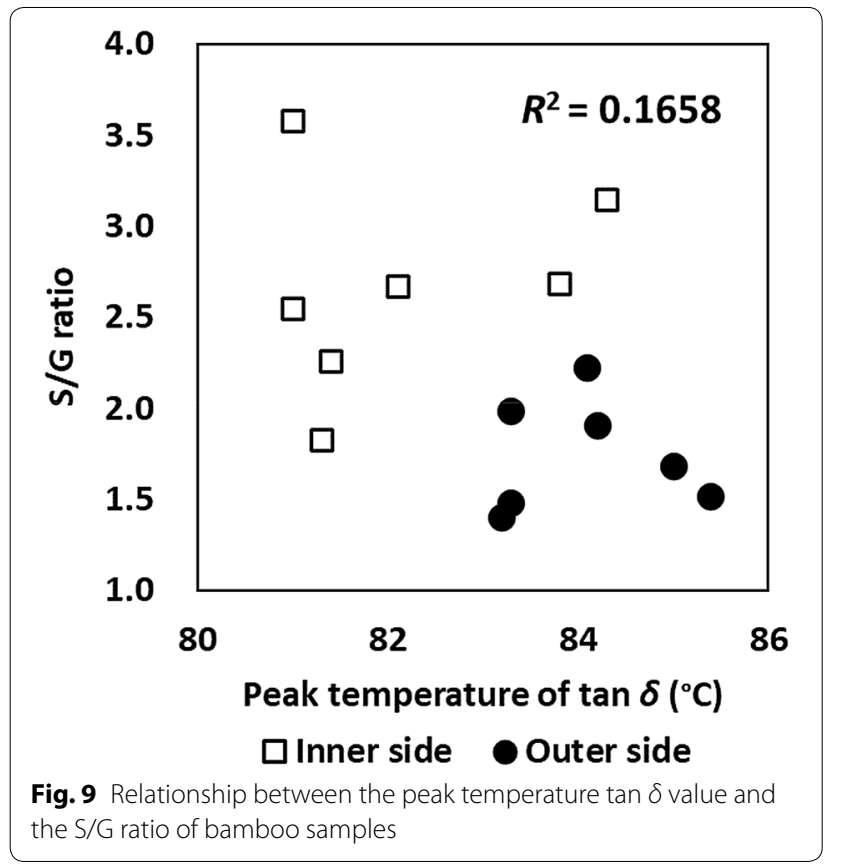

a higher content of $\mathrm{G}$ to $\mathrm{S}$ monomer. Moreover, the yield of thioacidolysis was lower on the outer vs. the inner side for almost all bamboo ages. Thioacidolysis proceeds mainly via cleavage of $\beta-O-4$ ether linkages. Several other types of bonding exist in lignins, such as $\beta-5, \beta-1, \beta-\beta$, $5-5$, and 4-O-5 bonds, which are resistant to degradation. The total yield and relative $S / G$ ratio of the thioacidolysis products closely reflect the amount and ring type of the lignin units that are involved in $\beta$-O-4 ether linkages [37]. These results suggest that the high frequency of $\beta-O-4$ ether linkages in lignin stem from the bamboo's inner side, rich in parenchyma cells. Moreover, the higher frequency of $\beta-O-4$ units on the inner side seemed to lead to a lower peak temperature $\tan \delta$ value. The higher peak temperature $\tan \delta$ may have been caused by the higher frequency of the non- $\beta-O-4$ ether bonds in softwood lignin, which consists mainly of $\mathrm{G}$ units $[27,38]$.

The $S / G$ ratio of the thioacidolysis products in the inner side was not constant with ages, while it was constant in outer side (Fig. 7). These differences in inner side could be due to changes of the yield of $\mathrm{S}$ thioacidolysis monomer (Fig. 6). The age-dependent differences of lignin structures might be varied between parenchyma and fiber cell.

While the yield of thioacidolysis and peak temperature $\tan \delta$ value increased until 3.5 Y. A recent study suggested that the formation rate of $\beta$-O-4 linkages differs during development of bamboo [24]. The proportion of $\beta$-O-4-linked $\mathrm{G}$ or $\mathrm{S}$ units with free phenolic groups was decreased in mature lignin compared with immature lignin, which indicates that the frequency of internal units increased with maturation [39]. The changes of lignin structures in bamboo could be continuing for 3 years. It was found that the glass transition temperature of lignin, the peak temperature of $\tan \delta$, was increased with increasing molecular weight $[40,41]$. The lower peak temperature $\tan \delta$ value might have occurred via lower polymerization degree of lignin in young bamboo such as $0.5 \mathrm{Y}$. On the other hand, the yield of thioacidolysis and peak temperature $\tan \delta$ value were decreased after $6.5 \mathrm{Y}$. This implies a decrease in the ratio of $\beta-O-4$ bonds in lignin, which suggests that lignin degradation might occur in old bamboo. It should be noted that there are two possible causes for the changes of the thioacidolysis yield: one is the changes of the amount of $\beta-O-4$ linkage the linkage as mentioned above, and the other is the changes of the amount of the linkage other than $\beta-O-4$. Thus, considerable possibility for the changes of thioacidolysis yields is by the lignin structure in newly formed cell wall layers in bamboo. It was indicated that the increase in the layer of parenchymal cells of Phyllostachys pubescens continued for 3-5 years, as assessed by microscopic observation [22]. Moreover, it was reported that cell wall formation may continue even in 12-year-old culms of Phyllostachys viridiglaucescens [23]. Liese and Weiner [23] reported that the unlignified lamellae deposited onto the lignified wall and also become lignified later in older culms of ages between 9 and 12 years. There is the potential for an increasing lignin with the linkage other than $\beta-O-4$ in newly formed cell walls of $6.5 \mathrm{Y}$ and after culms.

These changes in the dynamic viscoelastic properties of bamboo have a direct effect on bamboo processing. 
Moreover, knowledge about the effects of aging and related molecular changes of lignin polymers on natural plant materials' mechanical properties will be valuable for developing new polymer materials.

\section{Conclusion}

The age-dependent and radial sectional differences in bamboo's dynamic viscoelastic properties in the tangential direction, in relation to lignin structural variation, were evaluated. We measured dynamic viscoelasticity in the tangential direction and performed a thioacidolysis lignin analysis in samples obtained from bamboo of various ages. There was a clear age dependence in the peak temperature $\tan \delta$ value, i.e., $E^{\prime \prime} / E^{\prime}$, and in the yield of thioacidolysis in samples from both the inner and outer side of culms. The highest peak temperature $\tan \delta$ value was detected in $3.5 \mathrm{Y}$ bamboo, which contains the greatest amount of thioacidolysis products, i.e., $\beta$ - $O-4$ linkage of lignin. We hypothesized that the changes in bamboo's thermal softening properties that occur with aging are caused by the maturation and degradation of lignin in this plant. Moreover, the peak temperature $\tan \delta$ value was always higher on outer side and the ratio of S/G thioacidolysis products was always higher on inner side of culms in bamboo plants of all ages.

\section{Abbreviations}

$E^{\prime}$ : Storage elastic modulus; E": Loss modulus.

\section{Acknowledgements}

This work was supported by JSPS KAKENHI Grant Number JP17K17840. This research used Forest Biomass Analytical System (FBAS) provided by Research Institute for Sustainable Humanosphere (RISH), Kyoto University.

\section{Authors' contributions}

YO designed the study, collected and analyzed data and wrote the initial draft of the manuscript. KK, HA, TT, and YF contributed to dynamic viscoelastic analysis and interpretation of data, and assisted in the preparation of the manuscript. MY and TU contributed to lignin analytical data collection and interpretation, and critically reviewed the manuscript. All authors agree to be accountable for all aspects of the work in ensuring that questions related to the accuracy or integrity of any part of the work are appropriately investigated and resolved. All authors read and approved the final manuscript,

\section{Funding}

This work was supported by JSPS KAKENHI Grant Number JP17K17840.

\section{Availability of data and materials}

The datasets generated during and/or analyzed during the current study are available from the corresponding author on reasonable request.

\section{Competing interests}

The authors declare that they have no conflicts of interests.

\section{Author details}

${ }^{1}$ Fiber Science and Engineering, Kyoto Institute of Technology, Kyoto 606-8585, Japan. ${ }^{2}$ Graduate School of Life Environmental Science, Kyoto Prefectural University, Kyoto 606-8522, Japan. ${ }^{3}$ Research Institute for Sustainable Humanosphere, Kyoto University, Uji, Kyoto 611-0011, Japan. ${ }^{4}$ Research Unit for Development of Global Sustainability, Kyoto University, Uji, Kyoto 611-0011, Japan.
Received: 12 May 2020 Accepted: 14 September 2020

Published online: 25 September 2020

\section{References}

1. Banik RL (2015) Harvesting techniques. In: Liese W, Köhl M, eds. Bamboo: The plant and its uses. Springer: cham. pp 193-226.

2. Okahisa Y, Kojiro K, Kiryu T, Oki T, Furuta Y, Hongo C (2018) Nanostructural changes in bamboo cell walls with aging and their possible effects on mechanical properties. J Mater Sci 53:3972-3980

3. Kiryu T, Matsuda N, Kojiro K, Furuta Y (2017) The Mechanism of improvement of physical properties of moso bamboo (Phyllostachys pubescens) with increasing age II. Mokuzai Gakkaishi 63:14-20 (in Japanese)

4. Lybeer B, Van Acker J, Goetghebeur P (2006) Variability in fibre and parenchyma cell walls of temperate and tropical bamboo culms of different ages. Wood Sci Technol 40:477-492

5. Nakajima M, Furuta Y, Ishimaru Y, Ohkoshi M (2009) Cooling set and its recovery in water-saturated bamboo under large bending deformation. J Wood Sci 55:100-106

6. Zhan T, Jiang J, Lu J, Zhang Y, Chang J (2018) Influence of hygrothermal condition on dynamic viscoelasticity of Chinese fir (Cunninghamia lanceolata). Part 1: moisture adsorption. Holzforschung 72:567-578

7. Zhan T, Jiang J, Lu J, Zhang Y, Chang J (2019) Frequency-dependent viscoelastic properties of Chinese fir (Cunninghamia lanceolata) under hygrothermal conditions. Part 2: moisture desorption. Holzforschung 73:737-746

8. Wan G, Frazier T, Jorgensen J, Zhao B, Frazier C (2018) Rheology of transgenic switchgrass reveals practical aspects of biomass processing. Biotechnol Biofuels 11:57

9. Olsson A-M, Salmén L (1997) The effect of lignin structure on the viscoelastic properties of wood. Nord Pulp Pap Res J 12:140-144

10. Salmén L (1984) Viscoelastic properties of in situ lignin under watersaturated conditions. J Mater Sci 19:3090-3096

11. Furuta Y, Okuyama T, Kojiro K, Miyoshi Y, Kiryu T (2014) Temperature dependence of the dynamic viscoelasticity of bases of Japanese cypress branches and the trunk close to the branches saturated with water. J Wood Sci 60:249-254

12. Umezawa T (2010) The cinnamate/monolignol pathway Phytochem Rev 9:1-17

13. Barros J, Serk H, Granlund I, Pesquet E (2015) The cell biology of lignification in higher plants. Ann Bot 115:1053-1074

14. Umezawa T (2018) Lignin modification in planta for valorization. Phytochem Rev 17:1305-1327

15. Boerjan W, Ralph J, Baucher M (2003) Lignin biosynthesis. Annu Rev Plant Biol 54:519-546

16. Tobimatsu Y, Takano T, Umezawwa T, Ralph J (2019) Solution-state multidimensional NMR of lignins: Approaches and applications. In: Fachuang L, Fengxia $Y$ (eds) Lignin: Biosynthesis, functions and economic significance. Nova Science Publishers Inc, New York, pp 79-110

17. Bonawitz ND, Kim Jl, Tobimatsu Y, Ciesielski PN, Anderson NA, Ximenes EX, Maeda J, Ralph J, Donohoe BS, Ladisch M, Chapple C (2014) Disruption of mediator rescues the stunted growth of a lignin-deficient Arabidopsis mutant. Nature 509:376-380

18. Tarmadi D, Tobimatsu Y, Yamamura M, Miyamoto T, Miyagawa Y, Umezawa T, Yoshimura T (2018) NMR studies on lignocellulose deconstructions in the digestive system of the lower termite Coptotermes formosanus Shiraki. Sci Rep 8:1290

19. Cesarino I, Simões MS, dos Santos BM, Fanelli A, Silva T, Romanel E (2016) Building the wall: recent advances in understanding lignin metabolism in grasses. Acta Physiol Plant 38:269

20. Ralph J (2010) Hydroxycinnamates in lignification. Phytochem Rev 9:65-83

21. Lan W, Lu F, Regner M, Zhu Y, Rencorey J, Ralph S, Zakai U, Morreel K, Boerjan W, Ralph J (2015) Tricin, a flavonoid monomer in monocot lignification. Plant Physiol 167:1284-1295

22. Takabe K (2011) Chapter 1.1.9. In: Fukushima K, Funada R, Sugiyama J, Takabe K, Umezawa T, Yamamoto H (eds) Secondary xylem formationintroduction to biomass science-, 2nd edn. Otsu, Kaiseisha, pp 75-81

23. Liese W, Weiner $G$ (1996) Ageing of bamboo culms. A review Wood Sci Technol 30:77-89 
24. Tsuyama T, Shimada N, Motoda T, Matsushita Y, Kijidani Y, Fukushima K, Kamei I (2017) Lignification in developing culms of bamboo Sinobambusa tootsik. J Wood Sci 63:551-559

25. Tanahashi M, Higuchi T (1990) Effect of the hydrophobic regions of hemicelluloses on dehydrogenative polymerization of sinapyl alcohol. Mokuzai Gakkaishi 36:424-428

26. Takamura N (1968) Studies on hot pressing and drying process in production of fibreboard. III. Softening of fibre components in hot pressing of fibre mat. Mokuzai Gakkaishi 14:75-79

27. Sasaki Y, Okuyama T (1983) Residual stress and dimensional changes on heating green wood of Cryptomeria japonica. Mokuzai Gakkaishi 29:302-307

28. Furuta Y, Kohara M, Kanayama K (1999) Thermal-softening properties of water-swollen wood, 6: The change of thermal-softening properties due to lignification with moso bamboo [Phyllostachys pubesceus] as a model material. Mokuzai Gakkaishi 45:193-198 (in Japanese)

29. Suzuki S, Suzuki Y, Yamamoto N, Hattori T, Sakamoto M, Umezawa T (2009) High-throughput determination of thioglycolic acid lignin from rice. Plant Biotechnol 26:337-340

30. Yamamura M, Hattori T, Suzuki S, Shibata D, Umezawa T (2012) Microscale thioacidolysis method for the rapid analysis of $\beta-\mathrm{O}-4$ substructures in lignin. Plant Biotechnol 29:419-423

31. Yue F, Lu F, Sun R-C, Ralph J (2012) Syntheses of lignin-derived thioacidolysis monomers and their uses as quantitation standards. J Agric Food Chem 60:922-928

32. Chuma S, Hirohashi M, Ohgama T, Kasahara Y (1990) Composite structure and tensile properties of mousou bamboo. J Soc Mater Sci Japan 39:847-851 (in Japanese)

33. Bjurhager I, Olsson A-M, Zhang B, Gerber L, Kumar M, Berglund L, Burgert I, Sundberg B, Salmen L (2010) Ultrastructure and mechanical properties of Populus wood with reduced lignin content caused by transgenic down-regulation of cinnamate 4-hydroxylase. Biomacromology $11: 2359-2365$
34. Brunow G, Lundquist K (2010) Functional groups and bonding patterns in lignin (including the lignin-carbohydrate complexes). In: Heitner $\mathrm{H}$, Dimmel D, Schmidt J (eds) Lignin and lignans advances in chemistry, 1st edn. CRC Press, Boca Raton, pp 268-272

35. Tomimura Y, Yokoi T, Terashima N (1980) Heterogeneity in formation of lignin. V. Degree of condensation in guaiacyl nucleus. Mokuzai Gakkaishi 26:37-42

36. Baumberger S, Dole P, Lapierre C (2002) Using transgenic poplars to elucidate the relationship between the structure and the thermal properties of lignins. J Agric Food Chem 50:2450-2453

37. Lapierre C, Pollet B, Rolando C (1995) New insights into the molecular architecture of hardwood lignins by chemical degradative methods. Res Chem Intermed 21:397-412

38. Furuta Y, Nakajima M, Nakatani T, Kojiro K, Ishimaru Y (2008) Effects of the lignin on the thermal-softening properties of the water-swollen wood. J Soc Mater Sci Japan 57:344-349 (in Japanese)

39. Okahisa-Kobayashi Y (2016) Structural analysis of lignins and hemicelluloses in mature bamboo phyllostachys bambusoides culms for comparison with immature bamboo and other grass species. Int J Biomass Renewables 5:1-11

40. Yoshida H, Mörck R, Kringstad KP, Hatakeyama H (1987) Fractionation of kraft lignin by successive extraction with organic solvents. II. Thermal properties of kraft lignin fractions. Holzforschung 41:171-176

41. Kubo S, Uraki Y, Sano Y (1996) Thermomechanical analysis of isolated lignins. Holzforschung 50:144-150

\section{Publisher's Note}

Springer Nature remains neutral with regard to jurisdictional claims in published maps and institutional affiliations.

\section{Submit your manuscript to a SpringerOpen ${ }^{\circ}$ journal and benefit from:}

- Convenient online submission

- Rigorous peer review

- Open access: articles freely available online

- High visibility within the field

Retaining the copyright to your article

Submit your next manuscript at springeropen.com 